\title{
PENGARUH TINGKAT PENDIDIKAN DAN MOTIVASI KERJA TERHADAP PENDAPATAN MASYARAKAT DESA GIRIPURNO KECAMATAN BUMIAJI KOTA BATU
}

\author{
Dwi Handoko' ${ }^{1}$ Titik Purwati ${ }^{2}$ \\ 1Pendidikan Ekonomi, IKIP Budi Utomo \\ e-mail: uwiehunz30@gmail.com \\ 2Pendidikan Ekonomi, IKIP Budi Utomo \\ e-mail: titikpurwati62@gmail.com
}

\begin{abstract}
This study aims to determine the effect of education level and work motivation on community income in Giripurno village, Bumiaji sub-district, Batu city. This research is a quantitative study, the sample of respondents in this study were 39 people from a population of 433. Data were collected through a questionnaire and analyzed using descriptive analysis techniques and Multiple Regression analysis with the help of Eviews6 application. The results showed that the level of education and work motivation had a partial effect on people's income significantly. The level of education and work motivation simultaneously influence the people's income. From the research results obtained by $R$ square of 0.74 , meaning that $74 \%$ of the variable community income is influenced by the variables studied while the rest is influenced by variables not examined.
\end{abstract}

Keywords: Education Level, Work Motivation, Community Income

\begin{abstract}
Abstrak
Penelitian ini bertujuan untuk mengetahui pengaruh tingkat pendidikan dan motivasi kerja terhadap pendapatan masyarakat di desa Giripurno kecamatan Bumiaji kota Batu. Penelitian ini merupakan penelitian kuantitatif, sampel yang jadi responden dalam penelitian ini adalah 39 jiwa dari populasi yang berjumlah 433. Data dikumpulkan melalui angket dan dianalisis mengguanakan teknik analisis deskripsif dan analisis Regresi Berganda dengan bantuan aplikasi Eviews6. Hasil penelitian menunjukan bahwa tingkat pendidikan dan motivasi kerja berpengaruh secara parsial terhadap pendapatan masyarakat secara signifikan. Tingkat pendidikan dan motivasi kerja berpengaruh secara simultan terhadap pendapatan masyarakat. Dari hasil penelitian diperoleh $\mathrm{R}$ square sebesar 0,74 , artinya $74 \%$ variable pendapatan masyarakat
\end{abstract}


Volume 1, No. 2, Thn. 2019

http://ejurnal.budiutomomalang.ac.id/index.php/ecoducation

dipengaruhi oleh variabel yang diteliti sedangkan sisanya dipengaruhi oleh variabel yang tidak diteliti.

Kata kunci : Tingkat Pendidikan, Motivasi Kerja, Pendapatan Masyarakat 


\section{PENDAHULUAN}

Pendidikan memegang peranan penting dalam mempersiapkan sumber daya manusia yang berkualitas. Oleh karena itu pendidikan hendaknya dikelola dengan maksimal dan profesional, baik secara kualitas maupun kuantitas. Kondisi perekonomian merupakan dimensi penting dalam penyelenggaraan kebijakan negara untuk dapat dicapai secara optimal, kondisi perekonomian sering menjadi indikator kualitas sebuah negara ().

Hubungan antara pendidikan dan masyarakat terasa sangat penting sekali sehingga merupakan bidang studi tersendiri di dalam ilmu pendidikan. Hal ini tak lain merupakan akibat logis dari adanya pengembangan tujuan pendidikan bagi setiap orang untuk membentuk dirinya menjadi pribadi yang utuh, baik sebagai individu maupun sebagai anggota masyarakat yang sehat jasmani dan rohaninya, berilmu pegetahuan dan memiliki nilai moral yang baik.

Pemerintah melalui Depertemen Pendidikan dan Kebudayaan telah melakukan berbagai usaha untuk dapat menyelanggarakan pendidikan yang dapat menyentuh seluruh lapisan masyarakat dan selalu berusaha meningkatkan mutu pelaksanaan pendidikan. Namun hal tersebut belum dapat mewujudkan suatu bentuk pendidikan yang dapat di banggakan. Buktinya pemerintah telah mendirikan sekolah gratis, seperti paket B, dan paket C. Selain pendidikan motivasi juga merupakan salah satu faktor yang berhubungan dengan pendapatan, dimana motivasi merupakan sesuatu yang berasal dari diri orang dan memberikan arahan pada perilaku ().

Pendapatan Menurut Idrak (2010) adalah uang yang diterima oleh seseorang dan perusahaan dalam bentuk gaji, upah, sewa, bunga, dan laba, termasuk juga beragam tunjangan, seperti kesehatan dan pension. Menurut Basuki (2014) pendapatan perseorangan adalah jumlah pendapatan yang diterima oleh setiap orang dalam masyarakat, termasuk pendapatan yang diperoleh tanpa melakukan kegiatan apa pun. Menurut Moenier (2010: 79) menyatakan bahwa pendapatan adalah sebuah penerimaan seseorang sebagai imbalan atas tenaga kerja atau pikiran yang telah dicurahkan untuk orang lain atau badan organisasi baik dalam bentuk uang, maupun fasilitas dalam jangka waktu tertentu.

Motivasi dapat dikatakan sebagai perbedaan antara dapat melaksanakan dan mau melaksanakan, dimana motivasi adalah kekuatan baik dalam maupun dari luar yang mendorong seseorang untuk mencapai tujuan tertentu yang telah ditetapkan sebelumnya (Hamzah B. Uno, 2013). Sedangkan menurut Moenir (2010) motivasi adalah rangsangan dari luar dalam bentuk benda atau bukan benda yang dapat menumbuhkan dorongan pada orang untuk memiliki, menikmati, menguasai atau mencapai benda/ bukan benda tersebut.

Dari latar belakang di atas dirumuskan hipotesis sebagai berikut: 
- H1 : Terdapat pengaruh secara parsial antara tingkat pendidikan terhadap pendapatan masyarakat di desa Giripurno kecamatan Bumiaji kota Batu.

- H2 : Terdapat pengaruh secara parsial antara motivasi kerja terhadap pendapatan masyarakat di desa Giripurno kecamatan Bumiaji kota Batu.

- Ha : Terdapat pengaruh antara tingkat pendidikan dan motivasi kerja secara simultan terhadap pendapatan masyarakat di desa Giripurno kecamatan Bumiaji kota Batu.

\section{METODE PENELITIAN}

Pendekatan penelitian yang diigunakan oleh peneliti adalah pendekatan kuantitatif. Dimana pendekatan kuantitatif adalah penelitian yang datanya berupa angka-angka dan dianalisis dengan analisis untuk mencari jawaban dari rumusan masalah suatu penelitian. Sedangkan metode yang digunakan oleh peneliti adalah metode eksperimen. Penelitian pendekatan eksperimen adalah suatu penelitian yang berusaha mencari pengaruh variable tertentu terhadap variable yang lain dalam kondisi yang terkontrol secara ketat (Sugiyono, 2015).

Instrumen yang digunakan dalam penelitian ini yaitu berupa angket yang diberikan kepada Masyarakat Rt. 73, Rw. 11, desa Giripurno, kecamatan Bumiaji, kota Batu. Populasi yang digunakan dalam penelitian ini adalah pendudukan desa Giripurno, Rt. 73
Rw. 11, Kecamatan Bumiaji, Kota Batu terlihat pada tabel di bawah ini :

Tabel 1. Laporan Kependudukan

\begin{tabular}{|l|l|c|}
\hline No & Jenis Pekerjaan & Jumlah/orang \\
\hline 1. & Swasta/ Perusahaan & 94 \\
\hline 2. & Instansi pemerintah & 55 \\
\hline 3. & Petani atau pekebun & 284 \\
\hline \multicolumn{2}{|l|}{ Jumlah } & $\mathbf{4 3 3}$ \\
\hline \multicolumn{2}{|l|}{ Peneliti menggunakn } \\
\hline
\end{tabular}

simple random sampling dalam menentukan sampel data, dan menggunakan rumus Isaac dan Michael untuk menentukan jumlah sampelnya. Dengan menggunakan table diperoleh besaran sampel berdasarkan jumlah populasi sejumlah 39 orang, dengan taraf kesalahan 5\%.

Adapun deskripsi variabel dan indikator yang diteliti adalah sebagai berikut:

Tabel 2. Variabel dan Indikator Penelitian

\begin{tabular}{|c|c|c|}
\hline No & Variable & Indikator \\
\hline 1 & $\begin{array}{l}\text { Tingkat } \\
\text { Pendidikan (X1) } \\
\text { (Daryanto, 2013) }\end{array}$ & $\begin{array}{l}\text { Jenjang pendidikan: } \\
\text { - } \quad \text { Pendidikan Dasar } \\
\text { - } \quad \text { Pendidikan } \\
\text { Menengah } \\
\text { - } \quad \text { Pendidikan Atas }\end{array}$ \\
\hline 2 & $\begin{array}{l}\text { Motivasi kerja } \\
\text { (X2) } \\
\text { (Kadarisman, } \\
\text { 2012) }\end{array}$ & 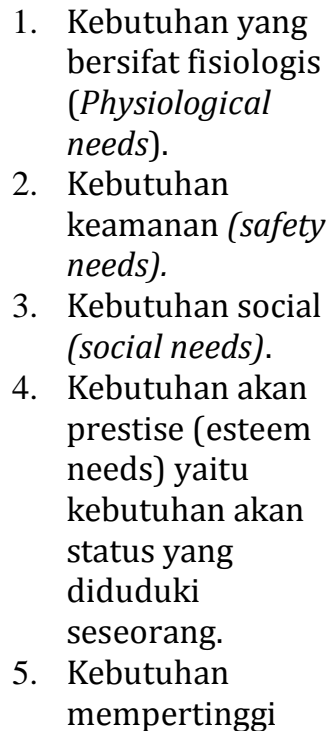 \\
\hline
\end{tabular}




\begin{tabular}{|c|l|l|}
\hline No & Variable & Indikator \\
\hline & & kapasitas kerja \\
& & (self \\
& & aktualization) \\
& & yaitu kebutuhan \\
& & untuk \\
& & mengembangkan \\
& & kapasitas mental \\
& & dari karyawan \\
& & melalui on the job \\
& & training, seminar, \\
& & lokakarya dan \\
& & sebagainya. \\
\hline \multirow{3}{*}{3} & Pendapatan (Y). & Pendapatan individu \\
& (Annes, 2015) & diperoleh dari \\
& & berbagai sumber. \\
\hline
\end{tabular}

Teknik Analisis yang digunakan dalam penelitian ini adalah sebagai berikut:

\section{Uji Coba Istrument}

Sebelum pengumpulan data yang sebenarnya dilakukan, angket yang akan digunakan terlebih dahulu diujicobakan. Pelaksanaan uji coba ini dimaksud untuk mengetahui kekurangan-kekurangan pada item angket, berkaitan dengan redaksi, alternatif jawaban yang tersedia maupun maksud yang terkandung dalam pernyataan item angket tersebut. Berdasarkan uraian diatas, penulis melakukan uji coba kepada responden. Data angket yang terkumpul, kemudian secara statistik dihitung validitas dan reabilitasnya.

\section{Uji Persyarat dan Analisis Uji Normalitas Data}

Uji normalitas bertujuan untuk menguji apakah sekelompok data berasal dari populasi berada dibawah kurva distribusi normal atau tidak. Model regresi yang baik adalah mempunyai distribusi normal atau mendekati normal pada nilai residual hasil regresi (Ghozali:2005).

\section{Uji Hipotesis}

Hipotesis merupakan jawaban sementara berdasarkan rumusan masalah yang ada. Bersifat sementara karena hipotesis diambil berdasarkan teori dan belum dibuktikan melalui penelitian. Dari hasil hipotesis selanjutnya dilakukan penelitian untuk mengetahui kebenaran atas hipotesis yang telah ada. Pengujian hipotesis dengan menggunakan analisis regresi linear berganda dilakukan untuk mengetahui pengaruh antara variabel independen dan variabel dependen secara keseluruhan.

\section{HASIL DAN PEMBAHASAN PENELITIAN}

Hasil jawaban responden yang berkaitan dengan tingkat pendidikan terakhir yang dicapai masyarakat yang bekerja dapat dilihat dalam tabel berikut:

Tabel 3. Tingkat Pendidikan Masyarakat

\begin{tabular}{|l|l|c|}
\hline No. & \multicolumn{1}{|c|}{ Tingkat Pendidikan } & Frekuensi \\
\hline 1 & Tidak Tamat Sekolah & 1 \\
\hline 2 & Sekolah Dasar (SD) & 9 \\
\hline 3 & $\begin{array}{l}\text { Sekolah Menengah } \\
\text { Pertama (SMP) }\end{array}$ & 9 \\
\hline 4 & $\begin{array}{l}\text { Sekolah Menengah Atas } \\
\text { SMA) }\end{array}$ & 10 \\
\hline 5 & Diploma & 3 \\
\hline 6 & Sarjana (S1) & 5 \\
\hline 7 & Magister (S2) & 2 \\
\hline
\end{tabular}

Motivasi kerja yang dimaksud adalah dorongan seseorang untuk melakukan suatu tindakan, jadi dalam penelitian ini didapat hasil analisis dari jawaban responden maka diperoleh Skor minimum yaitu 50 sedangkan Skor maksimum yaitu 105. 
Volume 1, No. 2, Thn. 2019

http://ejurnal.budiutomomalang.ac.id/index.php/ecoducation

Untuk mengetahui tinggi rendah nya motivasi kerja diperoleh kategori tingkat variabel berikut.

Tabel 4. Motivasi Kerja Kerja Masyarakat

\begin{tabular}{|c|c|c|c|}
\hline Interval & Frekuensi & Persentase & Kategori \\
\hline $95-105$ & 14 & 35,90 & $\begin{array}{c}\text { Sangat } \\
\text { setuju }\end{array}$ \\
\hline $84-94$ & 12 & 30,77 & Setuju \\
\hline $72-82$ & 9 & 23,08 & $\begin{array}{c}\text { Ragu- } \\
\text { ragu }\end{array}$ \\
\hline $61-71$ & 1 & 2,56 & $\begin{array}{c}\text { Tidak } \\
\text { setuju }\end{array}$ \\
\hline $50-60$ & 3 & 7,69 & $\begin{array}{c}\text { Sangat } \\
\text { tidak } \\
\text { setuju }\end{array}$ \\
\hline
\end{tabular}

Hasil pengelolaan data sekunder yang diperoleh dapat dilihat pendapatan masyarakat adalah sebagai berikut :

Table 5. Distribusi Frekuensi variabel Motivasi Kerja

\begin{tabular}{|c|c|c|c|}
\hline Interval & Frekuensi & Persentase & Kategori \\
\hline $\begin{array}{c}4.500 .000 \\
- \\
3.800 .000\end{array}$ & 3 & 8 & $\begin{array}{c}\text { Sangat } \\
\text { tinggi }\end{array}$ \\
\hline $\begin{array}{c}3.700 .000 \\
- \\
3.000 .000\end{array}$ & 10 & 25 & Tinggi \\
\hline $\begin{array}{c}2.900 .000 \\
-\end{array}$ & 13 & 33 & Sedang \\
2.100 .000 & & & \\
\hline $\begin{array}{c}2.000 .000 \\
-\end{array}$ & 12 & 31 & Rendah \\
1.300 .000 & & & \\
\hline$<$ & 1 & 3 & $\begin{array}{c}\text { Sangat } \\
\text { rendah }\end{array}$ \\
\hline \begin{tabular}{c}
1.200 .000 \\
\hline
\end{tabular} & & & \\
\hline
\end{tabular}

Hasil uji normalitas data diperoleh nilai JB sebesar 0,725 dan nilai probabilitas 0,690. Karena nilai JB atau $\chi 2$-hitung $(0,725)<\chi 2$-tabel $(5,991)$ dan nilai probabilitas $(0,695)$ $>0,005$, maka dapat disimpulkan bahwa data berdistribusi normal.
Hasil Analisis Regresi digunakan untuk mengetahui hubungan tingkat pendidikan dan motivasi kerja dengan pendapatan masyarakat di Desa Giripurno kecamatan Bumiaji Kota Batu. Dari hasil analisis data menggunakan analisis regresi berganda didapatkan hasil analisis sebagai berikut :

Tabel 6. Analisis Regresi Berganda

\begin{tabular}{|l|l|l|l|l|}
\hline $\begin{array}{l}\text { Variabe } \\
\text { l. }\end{array}$ & $\begin{array}{l}\text { Coeffici } \\
\text { ents }\end{array}$ & $\begin{array}{l}\text { Std.erro } \\
\text { r }\end{array}$ & $\begin{array}{l}\text { t- } \\
\text { stati } \\
\text { stic }\end{array}$ & Prob \\
\hline (Consta & 51932,5 & 580554, & 0,08 & 0,92 \\
nt) & 6 & 1 & 2,29 & 0,02 \\
Motivasi & 12640,9 & 5518,77 & 5,49 & 0,00 \\
kerja & 0 & 3 & 2,75 & 0,00 \\
(X2) & 240745 & 438226, & 2,24 & 0,03 \\
SD & 2 & 6 & 3,14 & 0,00 \\
SMP & 119568 & 433299, & 3,31 & 0,00 \\
SMA & 8 & 1 & 2,70 & 0,01 \\
Diploma & 987294, & 439912, & & \\
S1 & 71 & 7 & & \\
S2 & 478932 & 470158, & & \\
& 147769 & 4 & & \\
& 7 & 446013, & & \\
& 140869 & 0 & & \\
& 6 & 520372, & & \\
\hline
\end{tabular}

F hitung $=12,75$, $\mathrm{R}$ square $=0,742$, Fsig $=0,00$ Dependent Variabel : Pendapatan Masyarakat $\mathrm{Y}=\mathrm{a}+\beta 1 \mathrm{X} 1+\beta 2 \mathrm{D} 1+\beta 3 \mathrm{D} 2+\beta 4 \mathrm{D} 3+$ $\beta 2 \mathrm{D} 4+\beta 2 \mathrm{D} 5+\beta 2 \mathrm{D} 6$

Dari tabel hasil analisis regresi berganda diatas, diperoleh persamaan:

$\mathrm{Y}=51932,56+12640,90 \mathrm{X} 1+$ 2407452SD + 1195688SMP + 987294,7SMA + 1478932Diploma + $1477697 \mathrm{~S} 1+1408696 \mathrm{~S} 2$.

Didapatkan R2 = 0.742 atau 74,2\% bahwa : Hasil pengujian statistik variabel pengaruh tingkat pendidikan terhadap pendapatan masyarakat di Desa Giripurno kecamatan Bumiaji Kota Batu. 
Dimana nilai tingkat pendidikan Sekolah Dasar (SD) memilki nilai koefisien 2407452, dan tingkat signifikan $0,000<0,05$ (nilai $\alpha$ ) menunjukkan bahwa Tingkat pendidikan Sekolah Dasar (SD) dengan pendapatan masyarakat di Desa Giripurno kecamatan Bumiaji Kota Batu terdapat pengaruh yang signifikan, nilai tingkat pendidikan Sekolah Menengah Pertama dengan pendapatan masyarakat di Desa Giripurno kecamatan Bumiaji Kota Batu memiliki nilai koefisien 1195688, dan tingkat signifikan 0,009 $<0,05$ (nilai $\alpha$ ) menunjukan bahwa tingkat pendidikan Sekolah Menengah Pertama (SMP) dengan pendapatan masyarakat memiliki pengaruh yang signifikan, nilai tingkat pendidikan Sekolah Menengah Atas (SMA) memiliki nilai koefisien 987294,7 dan tingkat signifikan $0,03<0,05$ menunjukkan bahwa tingkat pendidikan SMA terhadap pendapatan masyarakat memiliki pengaruh yang signifikan, nilai tingkat pendidikan Diploma memiliki nilai koefisien 1478932, dan tingkat signifikan 0,003 $<0,05$ menunjukan bahwa tingkat pendidikan Diploma memiliki pengaruh yang signifikan, nilai tingkat pendidikan Sarjana (S1) memiliki nilai koefisien 1477697, dan tingkat signifikan 0,002 $<0,05$ menunjukkan bahwa tingkat pendidikan Sarjana memiliki pengaruh yang signifikan, nilai tingkat pendidikan Magister (S2) memiliki nilai koefisien 1408696, dan tingkat signifikan $0,01<0,05$ menunjukkan bahwa tingkat pendidikan Magister (S2) memiliki pengaruh yang signifikan. Sehingga bisa digunakan untuk memprediksikan pengaruh tingkat pendidikan terhadap pendapatan masyarakat di Desa Giripurno kecamatan Bumiaji Kota Batu.

Hasil pengujian statistik pengaruh motivasi kerja terhadap pendapatan masyarakat di Desa Renah Sungai Ipuh Kecematan Limbur Lubuk Mengkuang Muaro Bungo, dengan nilai koefisien 12640,90 , dan tingkat signifikan 0,02 $<0,05$ menunjukkan bahwa motivasi kerja dengan pendapatan masyarakat di Desa Giripurno kecamatan Bumiaji Kota Batu terdapat pengaruh yang signifikan sehingga bisa digunakan untuk memprediksikan pengaruh motivasi kerja terhadap pendapatan masyarakat di Giripurno kecamatan Bumiaji Kota Batu.

Hasil uji $F$ dapat dilihat bahwa hasil Fhitung sebesar 12,75 > Ftabel sebesar $=3,26$. Dan tingkat signifikansi sebesar 0,000 lebih kecil dari tingkat signifikansi yang digunakan 0,05 dengan kriteria pengambilan keputusan yaitu Fhitung $>$ Ftabel maka Ho ditolak dan $\mathrm{Ha}$ diterima, sehingga dapat disimpulkan bahwa tingkat pendidikan dan motivasi kerja berpengaruh terhadap pendapatan masyarakat di Desa Giripurno kecamatan Bumiaji Kota Batu.

\section{Pembahasan}

Penelitian ini merupakan penelitian kuantitatif yang bertujuan untuk meneliti pengaruh tingkat pendidikan dan motivasi kerja terhadap pendapatan masyarakat di Desa Giripurno kecamatan Bumiaji Kota Batu. Sesuai dengan rumusan 
masalah diantaranya (1) adakah terdapat pengaruh tingkat pendidikan terhadap pendapatan masyarakat di desa Giripurno kecamatan Bumiaji Kota Batu. (2) adakah terdapat pengaruh motivasi kerja terhadap pendapatan masyarakat di desa Giripurno kecamatan Bumiaji Kota Batu. (3) adakah terdapat pengaruh tingkat pendidikan dan motivasi kerja terhadap pendapatan masyarakat di desa Giripurno kecamatan Bumiaji Kota Batu.

\section{Pengaruh Tingkat Pendidikan Terhadap Pendapatan Masyarakat Desa Giripurno Kecamatan Bumiaji Kota Batu.}

Hasil analisis pengaruh tingkat pendidikan terhadap pendapatan masyarakat di desa Giripurno kecamatan Bumiaji Kota Batu. Menunjukkan bahwa adanya pengaruh positif dan signifikan antara tingkat pendidikan terhadap pendapatan masyarakat yang bekerja di instansi pemerintah, swasta/ perusahaan dan petani/ pekebun. Dalam Daryanto (2013: 27) tingkat pendidikan atau jenjang pendidikan adalah tahapan pendidikan yang diterapkan berdasarkan tingkat perkembangan peserta didik, tujuan yang akan dicapai, dan kemampuan yang dikembangkan. Berdasarkan hasil analisis data yang didapatkan oleh peniliti bahwa ada pengaruh yang signifikan antara tingkat pendidikan dengan pendapatan masyarakat di desa Giripurno kecamatan Bumiaji Kota Batu, dari data yang didapatkan masyarakat yang memiliki pendapatan tinggi, tingkat pendidikan tidak dapat dijadikan acuan bahwa tingkat pendidikan yang tinggi berpengaruh dengan pendapatan yang diterima oleh masyarakat yang bekerja.

Pengaruh Motivasi Kerja terhadap Pendapatan Masyarakat Desa Giripurno Kecamatan Bumiaji Kota Batu.

Hasil analisis pengaruh motivasi kerja terhadap pendapatan masyarakat di Desa Giripurno Kecamatan Bumiaji Kota Batu. Menunjukan bahwa adanya pengaruh positif dan signifikan antara motivasi kerja terhadap pendapatan masyarakat di Desa Giripurno Kecamatan Bumiaji Kota Batu. Hal ini menjelaskan bahwa motivasi kerja berpengaruh dengan pendapatan yang diterima oleh masyarakat.

Menurut Djaali (2013) motivasi kerja adalah kondisi fisiologis dan psikologis yang terdapat didalam diri pribadi seseorang yang mendorong untuk melakukan aktivitas kerja tertentu guna mencapai suatu tujuan.

Motivasi kerja yang dimaksud dalam penelitian ini adalah suatu dorongan atau kecenderungan hati seseorang untuk memperhatikan, menyukai, dan menginginkan terhadap tindakan, tindakan yang dimaksud adalah tindakan bekerja, kegiatan melaksanakan suatu pekerjaan untuk memperoleh keuntungan demi memenuhi kebutuhan dan berani menanggung resiko baik uang maupun waktu. Hal tersebut sejalan dengan penelitian hasil penelitian Cici Asterya Dewi (2012) berdasarkan hasil penelitian skripsi yang berjudul : "Pengaruh motivasi kerja terhadap kinerja Guru 
honorer di SMAN Rumpun IPS seKecematan Temanggung", di dapatkan hasil Koefisien regresi 0,381 dan tingkat signifikan sebesar 0,038<0,05 sehingga hipotesis motivasi kerja berpengaruh positif terhadap kinerja guru honorer diterima, artinya motivasi kerja mempunyai pengaruh terhadap kinerja guru honorer tetapi hubungan nya kecil. Sedangkan sisanya $85,4 \%$ dijelaskan oleh sebabsebab yang lain diluar variable motivasi kerja. Dari analisis dan penelitian yang relevan dapat disimpulkan dengan motivasi kerja tinggi maka akan memberi pengaruh yang positif kepada pendapatan yang diterima,walaupun hubungan nya kecil.

\section{Pengaruh Tingkat Pendidikan dan Motivasi Kerja terhadap Pendapatan Masyarakat di Desa Giripurno Kecamatan Bumiaji Kota Batu}

Hasil analisis secara bersamasama antara tingkat pendidikan dan motivasi kerja dengan pendapatan masyarakat dengan persamaan regresi yang diperoleh adalah $\mathrm{Y}=$ $51932,56+12640,90 \mathrm{X} 1+2407452 \mathrm{SD}$ + 1195688SMP + 987294,7SMA + 1478932Diploma + 1477697S1 + 1408696 S2. Hal inimenjelaskan bahwa tingkat pendidikan dan motivasi kerja berpengaruh terhadap pendapatan yang diterima oleh masyarakat, apabila motivasi kerja naik satuan maka pendapatan yang diterima akan naik juga.

Hasil penelitian ini sejalan dengan penelitian Helmati (2014: 172) tingkat pendidikan atau jenjang pendidikan adalah tahapan pendidikan yang ditetapkan berdasarkan tingkat perkembangan peserta didik, tujuan yang akan dicapai, dan kemampuan yang dikembangkan. Kemudian Winardi (2010: 9) menjelaskan pendapatan adalah sejumlah uang atau materi yang dicapai atas penggunaan kekayaan manusia bebas. Idrak (2010: 43) yang dimaksud dengan pendapatan adalah uang yang diterima oleh seseorang dan perusahaan dalam bentuk gaji, upah, sewa, bunga, dan laba, termasuk juga beragam tunjangan, seperti kesehatan dan pensiun

\section{KESIMPULAN}

Berdasarkan hasil penelitian secara keseluruhan diperoleh kesimpulan sebagai berikut:

Tingkat pendidikan terhadap pendapatan masyarakat memiliki pengaruh yang positif dan signifikan dengan pendapatan masyarakat yang bekerja di Desa Giripurno Kecamatan Bumiaji Kota Batu,

Motivasi kerja memiliki pengaruh dengan variabel pendapatan masyarakat yang bekerja di desa Giripurno Kecamatan Bumiaji Kota Batu, apabila seseorang memiliki motivasi yang tinggi maka akan mendorong seseorang untuk lebih giat lagi untuk bekerja, dan mencari peluang untuk bekerja agar mendapat pendapatan yang tinggi.

Secara simultan terdapat pengaruh yang signifikan antara tingkat pendidikan dan motivasi kerja terhadap pendapatan masyarakat dimana dilihat dari analisis yang telah dilakukan menggunakan regresi maka 
diperoleh nilai Fhitung $=12,75>$ dari $\mathrm{F}$ tabel $=3,26$, dan tingkat signifikan $0,000<0,05$.

\section{Saran}

Bagi masyarakat diharapkan menyadari bahwa pendapatan sangatlah penting untuk memenuhi kebutuhan, agar memperolah pendapatan yang tinggi maka perlu menumbuhkan suatu dorongan atau motivasi untuk bekerja lebih giat dan lebih efisien lagi, agar bisa memeperoleh pendapatan yang tinggi dan bisa memenuhi semua kebutuhan baik itu kebutuhan primer, sekunder dan tersier. Kepada peneliti selanjutnya agar dapat meneliti varaibel lainnya yang berhubungan dengan pendapatan.

\section{DAFTAR RUJUKAN}

Daryanto \& Farid, Mohammad. 2013. Konsep Dasar Manejemen Pendidikan di Sekolah. Yogyakarta: Gava Media.

Djaali. 2013. Psikologi pendidikan. jakarta: Bumi Aksara

Fitrisari, Ria, Annes, 2015, Skripsi, Pengaruh pelatihan dan pengalaman kerja terhadap pendapatan karyawan yoehas advertising, Universitas Jambi, JAMBI.

Helmawati. 2014. Pendidikan Keluarga Teoritis dan Praktis. Bandung: PT Remaja Rosdakarya

Indrak, M, dkk. 2010. Ekonomi Hafalan Luar Kepala. Yogyakarta: Messe Media

Kadarisman, M. 2012. Manajemen Pengembangan Sumber Daya Manusia. Jakarta: PT Rajagrafindo Persada
Moenir, H. A. S. 2010. Manajemen Pelayanan Umum Di Indonesia. Jakarta: Bumi Aksara

Pujoalwanto, Basuki. 2014. Perekonomian Indonesia tinjauan historis, teoritis, danempiris. Yogyakarta: Graha ilmu.

Sugiyono. 2013. Metode Penelitian Pendidikan Pendekatan Kuantitatif, Kualitatif, dan $R \& D$. Bandung: 